\title{
Thermal and hydrothermal alkaline modification of kaolin for the adsorptive removal of lead(II) ions from aqueous solution
}

\author{
Moses Kolade David ${ }^{1}$ (D . Uchechukwu Chris Okoro ${ }^{1} \cdot$ Kovo Godfrey Akpomie $^{1}$. Christian Okey ${ }^{1}$. \\ Henry Olumayowa Oluwasola ${ }^{1}$
}

Received: 3 February 2020 / Accepted: 26 March 2020 / Published online: 28 May 2020

(c) Springer Nature Switzerland AG 2020

\begin{abstract}
The properties of Enugu kaolin were modified by thermal and alkaline hydrothermal means. The raw and modified kaolin samples were characterized using Brunauer-Emmett-Teller nitrogen adsorption surface area analysis, X-ray fluorescence, $\mathrm{X}$-ray diffraction, Fourier-transform infrared spectroscopy and Scanning electron microscopy techniques. The effectiveness of the modified kaolin for the removal of lead(II) ions from aqueous solution was studied and compared to that of the raw kaolin sample. The results showed that the surface area of the modified samples increased from $19.170 \mathrm{~m}^{2} / \mathrm{g}$ to $247.889 \mathrm{~m}^{2} / \mathrm{g}, 208.745 \mathrm{~m}^{2} / \mathrm{g}$ and $221.608 \mathrm{~m}^{2} / \mathrm{g}$, followed by an increase in the pore volume for the modified samples. However, the modification led to a weak alteration to the kaolin structure. Residual ions detected by atomic absorption spectroscopy showed that the modified kaolin samples have improved removal efficiency for $\mathrm{Pb}$ (II) $(83 \%, 88 \%, 85 \%)$ when compared to the raw sample (33\%). The adsorption capacities of the raw kaolin and modified kaolin (sample C) were observed to increase with increase in contact time, initial metal ion concentration and adsorbent dose. The adsorption of $\mathrm{Pb}$ (II) unto the raw and modified kaolin followed Freundlich $\left(\mathrm{R}^{2}=0.9937\right)$ and Langmuir $\left(\mathrm{R}^{2}=0.9837\right)$ adsorption isotherm models respectively. The modified kaolin efficiently eliminated $\mathrm{Pb}$ (II) from aqueous solution. Enugu kaolin has the potential to be a catalyst-type material based on the surface analysis and adsorption experiments.
\end{abstract}

Keywords Kaolin $\cdot$ Hydrothermal $\cdot$ Adsorption $\cdot$ Heavy metals

$\begin{array}{ll}\text { Abbreviations } \\ \text { AAS } & \text { Atomic absorption spectroscopy } \\ \text { BET } & \text { Brunauer-Emmett-Teller } \\ \text { FT-IR } & \text { Fourier-transform infrared spectroscopy } \\ \text { IUPAC } & \text { International Union of Pure and Applied } \\ & \text { Chemistry } \\ \text { SEM } & \text { Scanning electron microscopy } \\ \text { XRD } & \text { X-ray diffraction } \\ \text { XRF } & \text { X-ray fluorescence }\end{array}$

\section{Background}

The rapid increase in the world population in the last 100 years and the vast industrial revolution has spiked the demand for fresh water and wastewater production. Due to the fact that the demand for fresh water is higher than supply, there is need therefore, for special treatment to obtain water of good quality and environmentally less hazardous effluents [1]. The aggressive usage of water domestically and industrially have made water contaminated by heavy metal ions very problematic in several parts of the world [2]. Heavy metals are toxic, stable and bio accumulative in nature and therefore considered as a

\footnotetext{
$\triangle$ Moses Kolade David, moses.david.pg79443@unn.edu.ng; Uchechukwu Chris Okoro, uchechukwu.okoro@unn.edu.ng; Kovo Godfrey Akpomie, kovo.akpomie@unn.edu.ng; Christian Okey, christian.okey@unn.edu.ng; Henry Olumayowa Oluwasola, henryoluwasola. pg00002@unn.edu.ng| 'Department of Pure and Industrial Chemistry, University of Nigeria Nsukka, Nsukka 410001, Enugu State, Nigeria.
} 
major environmental concern [3]. Most industrial waste waters carry detrimental amounts of heavy metals like lead, nickel and cadmium that goes into solution from pigments, metal coatings, photography and printing industries [4]. Humans and other living organisms react differently to heavy metal toxicity. Lead for example is harmful to the nervous system, liver and kidney. The world health organization stipulated that lead in drinking water must not exceed $0.07 \mathrm{mg} / \mathrm{L}$ [5]. Conventional ways to remove heavy metal contamination from wastewaters include electroplating, chemical coagulation, precipitation, ionexchange, membrane separation, and electro kinetics. Many of which are problematic as a result of associated limitations such as poor removal efficiency, unavailability, accumulation of large secondary waste, high cost of production and so on. From economic and efficiency stand point, adsorption method for the removal of heavy metal is regarded as the most promising and widely used [5-9]. Conventional adsorbents applied include activated carbon, alumina and silica $[6,10,11]$. Activated carbon, is regarded as one of the most important adsobent material used due to its high surface area, porousity and adsorption capacity. However, the use of activated carbon is limited because of its high cost of production [7, 9]. Kaolin has received considerable recognition as an adsorbent because of its high adsorption capacity [12].

Kaolin is a very important mineral of natural origin, which is being extensively used in industries due to its outstanding properties, which are but not limited to fine particle size, chemical inertness, brightness and so on. Kaolin clay may be made up of impurities such as quartz, illites, feldspar and so on whereas kaolinite forms the major part of the composition [13]. The ability of clay minerals to adsorb and exhibit catalytic properties drives the study of its physical and chemical properties, these properties are governed by the application of appropriate modification techniques to improve the extent and nature of their outer surface [14]. Several researchers have investigated the treatment or modification of clay minerals under two major distinct ways; physical modification involving the use of high temperature to influence the chemical composition and crystal structure and chemical modifications involving the alteration of the structure, surface functional groups and surface area by organic compounds, acids or bases [15]. A number of studies concerning kaolinite clay used to remove heavy metal ions from aqueous solution have been reported [16-20], demonstrating good adsorption consistency in all cases.

However, due to the fact that kaolin as a material is usually very un-reactive, enhancement of its properties by chemical method is problematic even when subjected to severe conditions of concentrated solutions and high temperatures. [21]. A metastable phase of kaolin have been observed to be more reactive when subjected to chemical treatment, this phase can be obtained by heating kaolin between $\approx 550$ and $950^{\circ} \mathrm{C}$ [22-24]. As a result of this treatment, there is removal of structural water and the structure of the kaolin is rearranged, retaining a small portion of $\mathrm{AlO}_{6}$ octahedra and converting the remaining structure into more reactive units of tetra and penta coordination. The heating temperature of kaolin affects its reactivity significantly, though the most favourable environment for obtaining a very reactive metakaolin have been reported by various authors to be between 600 and $800{ }^{\circ} \mathrm{C}$. [21-24].

The use of acids in the treatment of kaolin to enhance its surface area and catalytic properties have been observed to be very popular in research [25]. Various reports have been documented on the acid treatment of clays such as bentonite, smectite or montmorillonite, kaolin, and so on [13, 14, 21, 26-29]. There are several issues associated with the use of acid treated clays, such problems include corrosion of the process vessels, peroxide value present in oil products, increase in fatty acid and several other environmental issues [14]. There is less emphasis on the use of alkali or basses in the treatment of clay in literature. Theoretically, it is expected that there would be a continuous leaching of aluminic and silicic layers because both elements can dissolve under alkaline conditions. The mineral structure is not significantly altered with the formation of new phases under alkaline conditions as reported by Taubald et al. [30] who observed no significant difference in the diffraction peaks of smectite and smectite treated in alkaline solution. Hussin et al. [15] also reported the increase in active centers and decrease in surface area when kaolin clay was treated with $\mathrm{NaOH}$.

Despite the studies described above, accounts on the effects of combined physical thermal activation and chemical hydrothermal treatment of kaolin under alkaline condition on its chemical, surface area/pore properties as well as heavy metal adsorption study are lacking in literature and since clay minerals are natural, common and inexpensive, there is increasing interest in investigating new applications. In this study, raw and modified kaolin were investigated for the removal of $\mathrm{Pb}$ (II) from aqueous solution. Specifically, the study sought to modify Enugu kaolin under thermal and alkaline hydrothermal conditions and study the changes in its physicochemical properties via BET, XRF, SEM, XRD and FTIR analytical techniques. The conditions for adsorption including contact time, initial $\mathrm{Pb}$ (II) concentration and adsorbent dosage were optimized with respect to the efficiency of $\mathrm{Pb}$ (II) ions removed. Furthermore, equilibrium studies were employed using various adsorption isotherms to better understand the adsorption of $\mathrm{Pb}$ (II) onto the raw and modified kaolin samples and comparison with other investigations into other 
adsorbents that have been used to remove $\mathrm{Pb}$ (II) ions from aqueous solutions were presented.

\section{Methods}

$1 \mathrm{~kg}$ of natural kaolin clay originating from Enugu State (Nigeria) was procured from Ogigie market in Nsukka and was used without pretreatment. The reagents utilized in this study were of laboratory standard. Sodium hydroxide pellets $(98 \%)$ and lead nitrate $(99 \%)$ were procured from Qualikems (India). Hydrochloric acid was procured from Joechem ventures (Nigeria). Only distilled water and deionized water were used in this study.

\subsection{Thermal/hydrothermal treatment}

Prior to the hydrothermal treatment, raw kaolin was first subjected to thermal activation into metakaolin [22-24]. This process involved the heating of a weighted quantity of the raw kaolin in a muffle furnace at a temperature of $800^{\circ} \mathrm{C}$ for $2 \mathrm{~h}$. A reaction mixture was obtained by mixing $3.0 \mathrm{~g}$ of metakaolin with $70 \mathrm{~mL}$ of 1.5 and 2.5 molar solutions of $\mathrm{NaOH}$ prepared earlier by dissolving appropriate amounts of the pellets in deionized water. The mixture was stirred to homogeneity then transferred into a $100 \mathrm{~mL}$ cylindrical poly tetrafluoroethylene (PTFE) vessel and placed in a high-pressure stainless-steel autoclave. For the hydrothermal reaction, the autoclave was placed in an oven at a temperature of $100^{\circ} \mathrm{C}$ for $7-11 \mathrm{~h}$. At the end of the reaction time, the autoclave was brought out of the oven and cooled in a water bath to stop the reaction and overlaying alkaline solution was discarded. The mixture was filtered and the residue was washed to remove excess alkaline then dried at temperature of $80^{\circ} \mathrm{C}$ overnight and were packaged for characterization. Three samples labeled $B, C$ and $D$ where prepared with varying conditions of $2.5 \mathrm{M} \mathrm{NaOH} / 7 \mathrm{~h}, 1.5 \mathrm{M} \mathrm{NaOH} / 8 \mathrm{~h}$ and $1.5 \mathrm{M} \mathrm{NaOH} / 11 \mathrm{~h}$ respectively and the raw kaolin was labeled as sample $\mathrm{A}$.

\subsection{Characterization techniques}

Brunauer-Emmett-Teller (BET) nitrogen adsorption surface area analysis was conducted at the Center for Generic Engineering and Biotechnology, Federal University of Technology Minna, Nigeria using Na 4200e Surface Area and Pore Analyzer. X-ray diffraction (XRD) was carried out using Empyrean by Panalytical, the morphology of the sample particles was observed using the Thermo Scientific $^{\mathrm{TM}}$ Q250 scanning electron microscope (SEM), Fouriertransform infrared spectroscopy (FTIR) was done using the Agilent Cary 630 FTIR spectrometer, and the mineralogical analysis was carried out using Oxford's X-Supreme 8000
X-ray fluorescence (XRF) Analyzer at the Department of Chemical Engineering, Ahmadu Bello University Zaria. The remaining concentration of heavy metals in the sorption medium was determined using an automated Shimadzu's AA-7000 Atomic Adsorption Spectrophotometer at the Center for Energy Research and Development, University of Nigeria. Statistical analysis was performed using statistical software packages.

\subsection{Adsorption experiments}

To determine the effectiveness of the samples in adsorbing $\mathrm{Pb}(\mathrm{II})$, a solution of $225 \mathrm{mg} / \mathrm{L}$ of lead nitrate was prepared by dissolving a weighted amount of the salt in deionized water. $50 \mathrm{~mL}$ of the lead solution was left in contact with $0.5 \mathrm{~g}$ of samples $\mathrm{A}, \mathrm{B}, \mathrm{C}$, and $\mathrm{D}$ and the $\mathrm{pH}$ were adjusted to 6 using $0.5 \mathrm{M} \mathrm{HCl}$ and $0.1 \mathrm{M} \mathrm{NaOH}$ solutions. At this $\mathrm{pH}$, only $0.6 \%$ of the metal ion precipitated, which is consistent with the optimum $\mathrm{pH}$ range for the adsorption of $\mathrm{Pb}(\mathrm{II})$ as reported in previous studies [31, 32]. The mixtures were stirred constantly at $250 \mathrm{rpm}$ on a magnetic stirrer for $20 \mathrm{~min}$ and at temperature of $50^{\circ} \mathrm{C}$ (optimum temperature in preliminary tests). The amount of $\mathrm{Pb}$ (II) adsorption at equilibrium $\mathrm{q}_{\mathrm{e}}(\mathrm{mg} / \mathrm{g})$ and the removal efficiency $(\mathrm{R})$ were calculated from the following equations:

$q_{e}=\frac{V\left(C_{0}-C_{e}\right)}{W}$

$R=\frac{C_{0}-C_{e}}{C_{0}} \times 100$

where $\mathrm{q}_{\mathrm{e}}$ is the equilibrium adsorption capacity of adsorbent in $\mathrm{mg}$ (metal)/g (adsorbent), $\mathrm{C}_{0}$ is the concentration of metal ions before adsorption in $\mathrm{mg} / \mathrm{L}, \mathrm{Ce}$ is the equilibrium concentration of metal ions in $\mathrm{mg} / \mathrm{L}, \mathrm{V}$ is the volume of metal ions solution in liter scale, $\mathrm{W}$ is the weight of the adsorbent in gram scale and $\mathrm{R}$ is the removal efficiency measured in percentage.

\subsection{Batch adsorption studies}

The adsorption of $\mathrm{Pb}$ (II) unto the raw and modified kaolin were studied using the batch technique, including the effects of contact time, adsorbent dosage and initial metal ion concentration. $0.5 \mathrm{~g}$ of the adsorbents were left in contact with $225 \mathrm{mg} / \mathrm{L} \mathrm{Pb}$ (II) solution for 10-30 min to study the effect of contact time. For the effects of initial metal ion concentration, $\mathrm{Pb}$ (II) solutions of $100-225 \mathrm{mg} / \mathrm{L}$ were left in contact with $0.5 \mathrm{~g}$ adsorbent for $20 \mathrm{~min}$, while the effects of adsorbent dosage were studied by contacting $0.3-0.7 \mathrm{~g}$ of the adsorbents with $225 \mathrm{mg} / \mathrm{L} \mathrm{Pb}$ (II) solution for $20 \mathrm{~min}$. 


\subsection{Adsorption isotherm models}

\subsubsection{Langmuir isotherm}

This isotherm exhibits a monolayer sort of sorption on an adsorbent having a limited number of indistinguishable binding sites (homogeneous surface). The linear form of the Langmuir equation can be expressed as [33]:

$\frac{C_{e}}{C_{e}}=\frac{1}{q_{L} K_{L}}+\frac{C_{e}}{q_{L}}$

where $\mathrm{q}_{\mathrm{e}}(\mathrm{mg} / \mathrm{g})$ denotes the adsorption capacity and $\mathrm{K}_{\mathrm{L}}$ $(\mathrm{L} / \mathrm{mg})$ denotes energy of adsorption. The essential characteristics of the Langmuir isotherm is described by a dimensionless factor $R_{L}$ given by:

$R_{L}=\frac{1}{\left[1+K_{L C_{0}}\right]}$

The $R_{L}$ values describe the type of adsorption to be irreversible $\left(R_{L}=0\right)$, favorable $\left(0<R_{L}<1\right)$, linear $\left(R_{L}=1\right)$ or unfavorable $\left(R_{L}>1\right)$.

\subsubsection{Freundlich isotherm}

This type of isotherm is aimed at describing a multilayer adsorption unto a heterogeneous surface of an adsorbent. The linearized form of Freundlich equation is expressed thus [34]:

$\log q_{e}=\log K_{f}+\left[\frac{1}{n}\right] \log C_{e}$

where $\mathrm{K}_{\mathrm{F}}(\mathrm{L} / \mathrm{g})$ and $\mathrm{n}$ are the Freundlich constants denoting adsorption capacity and intensity respectively.

\subsubsection{Temkin isotherm}

The Temkin isotherm model relates to the interaction between the metal ions and the adsorbent species assuming that the free energy is a function of surface coverage. The linearized equation is expressed as [31]:

$q_{e}=B \ln A+B \ln C_{e}$

where $B(\mathrm{mg} / \mathrm{g})$ is related to the heat of adsorption and $A$ $(\mathrm{L} / \mathrm{mg})$ represents the equilibrium binding constant corresponding to the maximum energy.

\section{Results}

\subsection{BET surface area analysis}

Brunauer-Emmett-Teller (BET) theory aims to explain the physical adsorption of gas molecules on a solid surface and serves as the basis for an important analytic technique for the measurement of the specific surface area of materials and pore size distribution. Before the analysis, the samples were left in desiccators to ensure that they have as little remaining water vapor as possible. The analysis gas was nitrogen and the samples were out gassed at $250^{\circ} \mathrm{C}$ for $3 \mathrm{~h}$. The data obtained from the analysis for surface area and pore parameters are summarized in the Table 1. The average pore diameter was calculated using the Wheeling equation [35] expressed as:

$P_{d}=4000 \times \frac{V}{S}$

where $P_{d}$ is pore diameter $(\mathrm{nm}), V$ is pore volume $(\mathrm{cc} / \mathrm{g})$ and $S$ represents the surface area.

From the data presented in Table 1, it was found that the BET surface area of sample A (raw kaolin) is measured at $19.170 \mathrm{~m}^{2} / \mathrm{g}$. The surface area of sample $B$ increased to $247.889 \mathrm{~m}^{2} / \mathrm{g}$ when treated hydrothermally with $2.5 \mathrm{M}$ $\mathrm{NaOH}$ at $100^{\circ} \mathrm{C}$ for $7 \mathrm{~h}$. The surface area for sample $\mathrm{C}$ was observed to have increased to $208.745 \mathrm{~m}^{2} / \mathrm{g}$ after the raw kaolin was hydrothermally reacted with $1.5 \mathrm{M} \mathrm{NaOH}$ at $100^{\circ} \mathrm{C}$ for $8 \mathrm{~h}$. In the same way, the surface area of sample $D$ increased to $221.608 \mathrm{~m}^{2} / \mathrm{g}$ after increasing the time of hydrothermal reaction with $1.5 \mathrm{M} \mathrm{NaOH}$ at $100^{\circ} \mathrm{C}$ to $11 \mathrm{~h}$. The pore volume increased from $0.006504 \mathrm{cc} / \mathrm{g}$ in the raw kaolin to $0.6884,0.0889$ and $0.0642 \mathrm{cc} / \mathrm{g}$ in the treated samples $B, C$ and $D$ respectively. This is followed by a drop in pore diameter from $1.36 \mathrm{~nm}$ in sample $A$ to a minimum value of $1.08 \mathrm{~nm}$ in the modified samples as shown in Table 1.

Table 1 BET surface area and pore size distribution of the raw and modified kaolin samples

\begin{tabular}{lcll}
\hline Samples & $\begin{array}{l}\text { Surface area } \\
\left(\mathrm{m}^{2} / \mathrm{g}\right)\end{array}$ & $\begin{array}{l}\text { Pore volume } \\
(\mathrm{cc} / \mathrm{g})\end{array}$ & $\begin{array}{l}\text { Pore diam- } \\
\text { eter }(\mathrm{nm})\end{array}$ \\
\hline A & 19.17 & 0.0065 & 1.36 \\
B & 247.89 & 0.0884 & 1.08 \\
C & 208.75 & 0.0889 & 1.32 \\
D & 221.61 & 0.0642 & 1.16 \\
\hline
\end{tabular}




\subsection{Characterization}

Mineralogical investigation of the raw and modified kaolin was carried out, results indicated that the raw kaolin deposits are majorly composed of kaolinite, quartz, and hematite and trace amounts of anatase and periclase. The chemical composition is presented in Table 2 . Hydrothermal treatment of metakaolin with $1.5 \mathrm{M} \mathrm{NaOH}$ for $8 \mathrm{~h}$ led to insignificant changes in the composition of the kaolin. The XRD patterns of the raw and modified kaolin are presented in Fig. 1, both kaolin and the modified sample showed well-defined reflection peaks at $2 \theta$ values of $8^{\circ}$ and $20^{\circ}-25^{\circ}$. The morphology of raw and modified kaolin were examined under an electron microscope. The SEM micrographs of the raw and modified kaolin are presented in Fig. 2, while the FTIR spectra of the raw and modified kaolin are shown in Figs. 3.

\subsection{Performance assessment}

$\mathrm{Pb}$ (II) adsorption capacities of the samples are presented in Fig. 6. The raw kaolin showed adsorption capacity of $7.3 \mathrm{mg} / \mathrm{g}$ with a removal efficiency of $33 \%$. Samples B, C and D have adsorption capacities of $18.65 \mathrm{mg} / \mathrm{g}, 19.7 \mathrm{mg} / \mathrm{g}$ and $19.13 \mathrm{mg} / \mathrm{g}$ with removal efficiencies of $83 \%, 88 \%$ and at $85 \%$ respectively. The adsorption capacities of the raw and modified were observed to increase with increase in contact time, initial metal ion concentration and adsorbent dose. The adsorption of $\mathrm{Pb}$ (II) onto the raw kaolin and the modified one followed Freundlich and Langmuir adsorption isotherm models respectively.

\section{Discussion}

\subsection{Physcochemical characterization of adsorbents}

The surface area of the raw kaolin $\left(19.170 \mathrm{~m}^{2} / \mathrm{g}\right)$ falls between the ranges of $5-25 \mathrm{~m}^{2} / \mathrm{g}$ as reported to by Emam et al. [36], Edama et al. [13] and Belver et al. [21] to be the specific surface area of unmodified kaolin. It was found that the modified kaolin samples had significantly larger surface areas up to about 1,193\% increase when compared to the unreacted one which is a desirable property of an adsorbent because high surface area is required for optimum adsorption [37]. These results are significantly higher than that obtained by Emam et al. [36] and Edama et al. [13] showing that hydrothermal treatment under alkaline conditions better enhances the expansion of the surface area of kaolin. This expansion

Table 2 Chemical composition of the raw and modified kaolin

\begin{tabular}{lllllllllllllllll}
\hline Elements (wt\%) & $\mathrm{Na}_{2} \mathrm{O}$ & $\mathrm{MgO}$ & $\mathrm{Al}_{2} \mathrm{O}_{3}$ & $\mathrm{SiO}_{2}$ & $\mathrm{P}_{2} \mathrm{O}_{5}$ & $\mathrm{SO}_{3}$ & $\mathrm{Cl}$ & $\mathrm{K}_{2} \mathrm{O}$ & $\mathrm{CaO}$ & $\mathrm{TiO}_{2}$ & $\mathrm{Cr}_{2} \mathrm{O}_{3}$ & $\mathrm{Mn}_{2} \mathrm{O}_{3}$ & $\mathrm{Fe}_{2} \mathrm{O}_{3}$ & $\mathrm{ZnO}$ & $\mathrm{SrO}$ \\
\hline Raw kaolin & 0.00 & 3.80 & 19.45 & 60.34 & 0.01 & 0.30 & 0.02 & 0.80 & 0.88 & 1.88 & 1.85 & 0.22 & 12.19 & 0.02 & 0.03 \\
Modified Kaolin & 6.73 & 4.23 & 19.49 & 52.67 & 0.00 & 0.22 & 0.04 & 0.057 & 1.06 & 1.95 & 0.04 & 0.21 & 12.75 & 0.03 & 0.03 \\
\hline
\end{tabular}

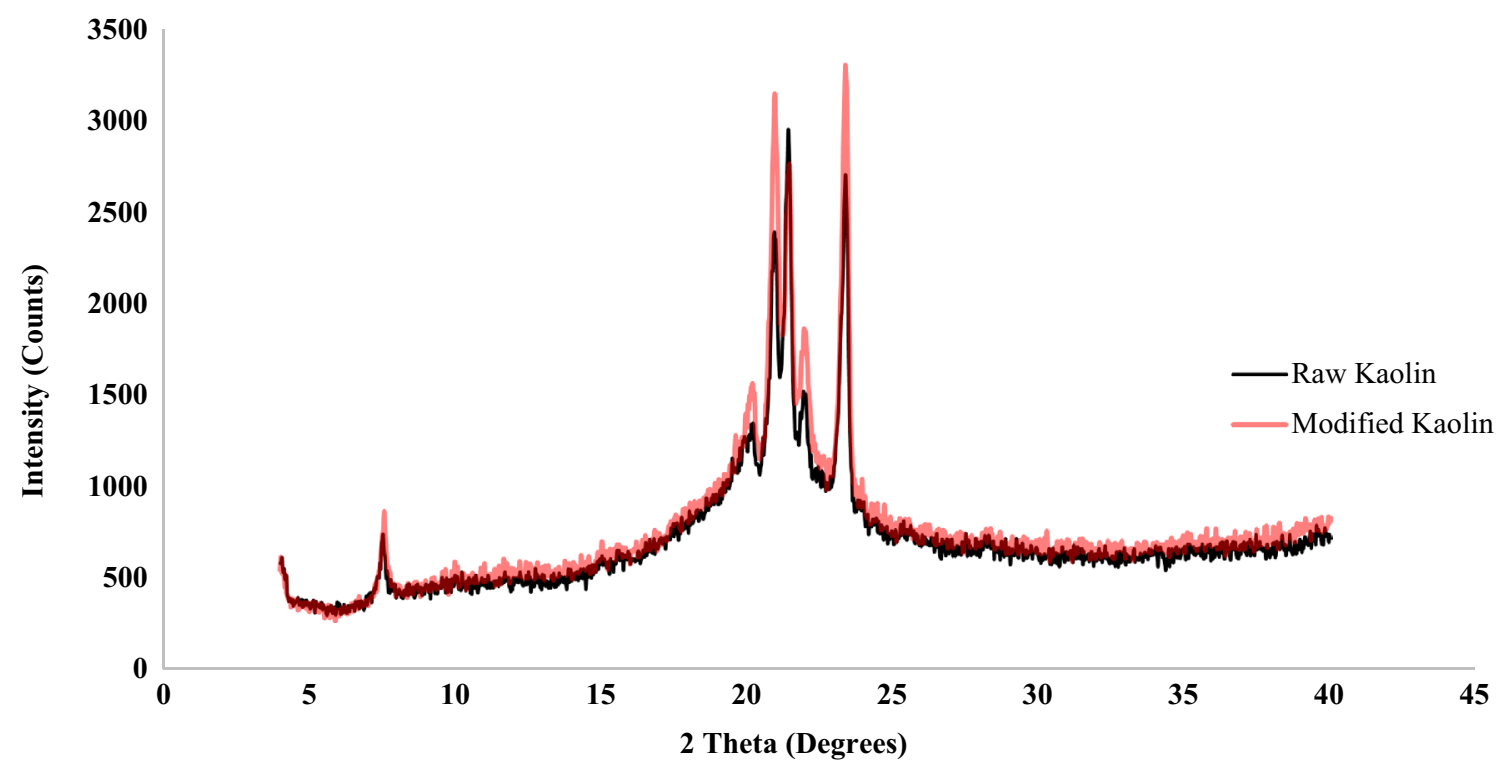

Fig. 1 XRD pattern for the raw and modified kaolin 

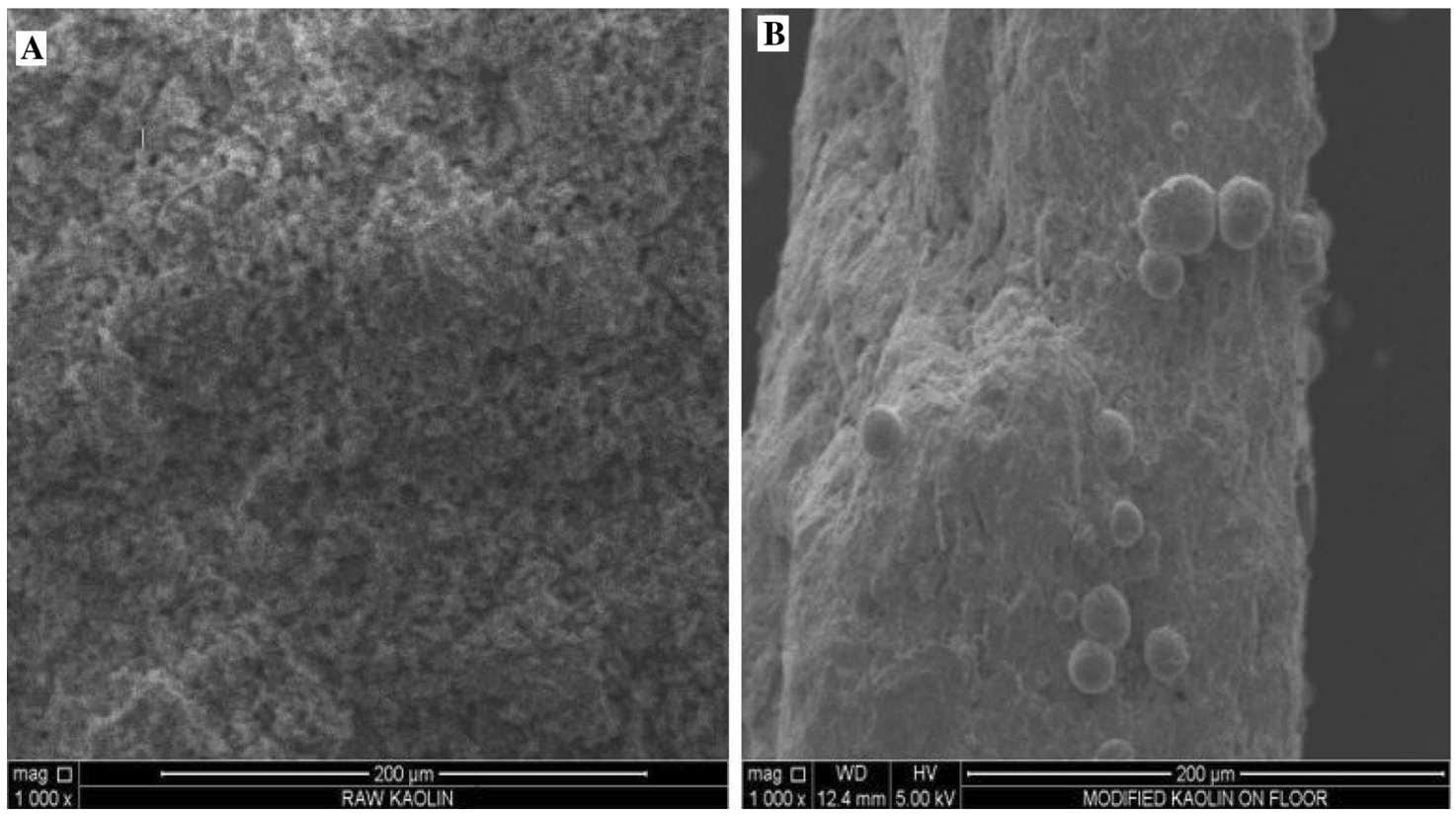

Fig. 2 SEM micrographs of the raw and modified kaolin

according to Akpomie and Dawodu [31] can be attributed to increase in pore properties caused by etching reaction between silica and a strong base. The authors maintained that other factors such as the type and purity of the clay, the cation saturation, the out-gassing temperature and sample pretreatment could also contribute the extent to which the surface of the clay changed after the modification.

Results from XRF shows observable loss of $7.7 \% \mathrm{SiO}_{2}$ from the raw kaolin due to the removal of quartz impurities during the hydrothermal reaction and the fixation of about $6.7 \% \mathrm{NaO}_{2}$ due to the insertion of $\mathrm{Na}^{+}$into the kaolinite structure. The peaks shown on the XRD spectra are peculiar characteristic peaks of kaolinite $[14,36]$. These peaks were also noticeable in the modified kaolin showing that the modification made weak alterations to the structure of the kaolin. However, the intensity of most of the peaks in the modified kaolin spectra were observed to have increased and this increase may be due to the increase of crystallite size and/or the decrease of the mean lattice strain. The SEM micrographs in Fig. $2 \mathrm{~b}$ showed spherical shaped crystals formed on the modified kaolin, this kind of morphology was also observed by José et al. [38], Khatamian and Irani [39], Shaikh et al. [40]. When compared to the SEM micrographs of raw kaolin in Fig. 2a, it can be observed that the raw kaolin has mainly amorphous structure. FTIR spectra in Fig. 3 shows broad band at $3291 \mathrm{~cm}^{-1}$ and the sharp peak at $1640 \mathrm{~cm}^{-1}$ which can be associated to structural hydroxyl groups and bending mode of adsorbed water. The band around $1148 \mathrm{~cm}^{-1}$ represents $\mathrm{T}-\mathrm{O}(\mathrm{T}=\mathrm{Si}$ or $\mathrm{Al})$ symmetric stretching $[41,42]$. Asymmetric and symmetric stretching vibrations bands of T-O-T bridges are at $1077 \mathrm{~cm}^{-1}$ and $760 \mathrm{~cm}^{-1}$. Similar bands can also be noticed in the raw kaolin spectra, this is to confirm that the kaolinite structure was not vigorously altered by the reaction.

The uptake of lead onto the raw kaolin was lower ( $7.3 \mathrm{mg} / \mathrm{g}$ at $33 \%$ efficiency) when compared to all the hydrothermally treated samples. This corroborates previous studies comparing the uptake of different heavy metals onto unmodified and modified kaolin [16, 32]. From Fig. 4 , it is clear that sample $C$ has the highest adsorption capacity of $19.7 \mathrm{mg} / \mathrm{g}$ with a removal efficiency of $88 \%$ when compared to samples B and D $(18.65 \mathrm{mg} / \mathrm{g}$ at $83 \%$ and $19.13 \mathrm{mg} / \mathrm{g}$ at $85 \%$ respectively). Generally, adsorption capacity increased when the concentration of $\mathrm{NaOH}$ was reduced from 2.5 to $1.5 \mathrm{M}$, indicating that using lower alkalinity contributes to the improvement of the $\mathrm{Pb}$ (II) uptake capacity. The reaction time also had a slight effect on the adsorption capacity of lead, it was observed that the adsorption capacity dropped slightly when the reaction time was increased from 8 to $11 \mathrm{~h}$ at the same alkaline conditions. These results validate that Enugu kaolin is a promising source of raw minerals for the synthesis of lowcost adsorbents.

\subsection{Effect of contact time}

Figure 5 shows the effect of contact time on the adsorption of $\mathrm{Pb}$ (II) onto raw and modified kaolin. It was observed 
A Raw Kaolin

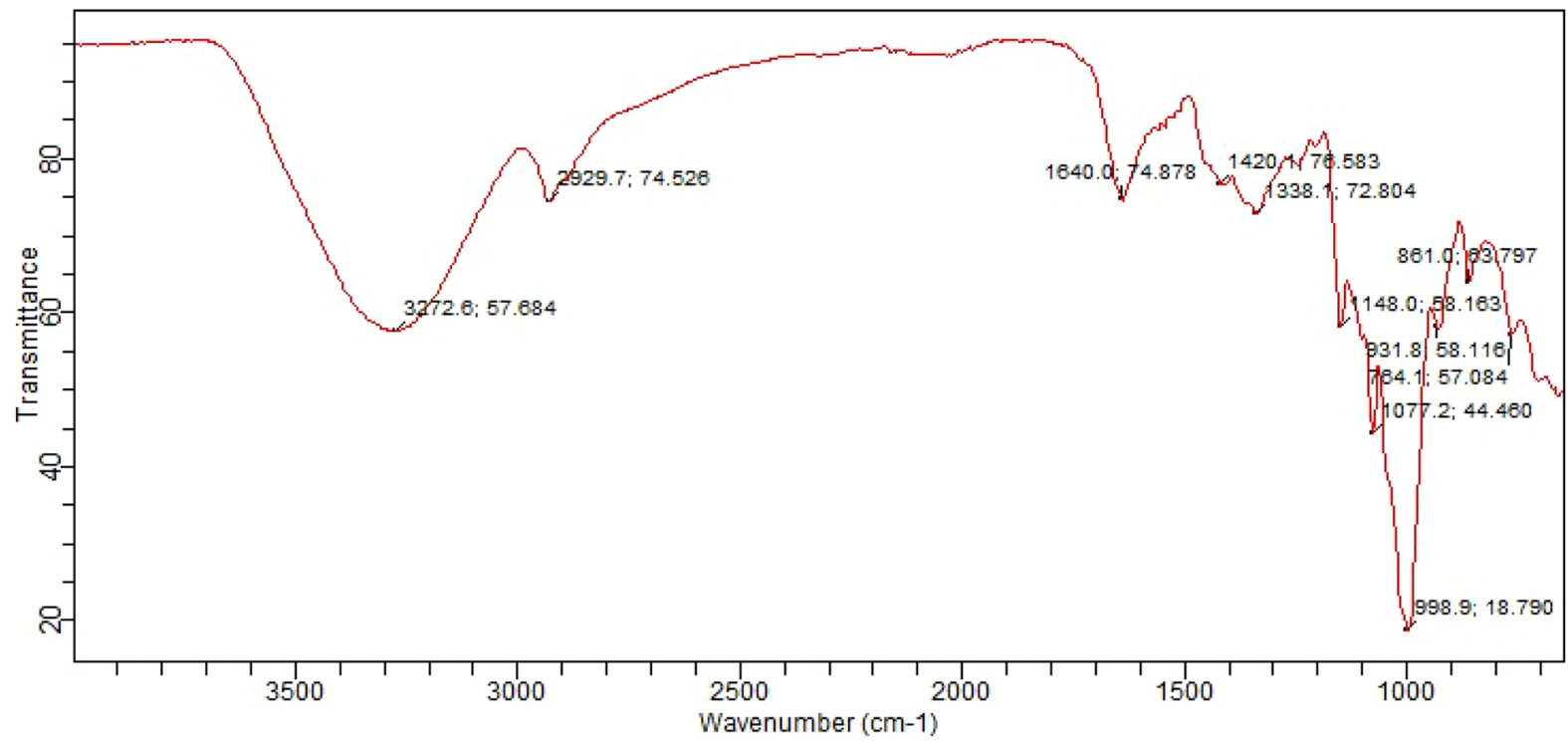

B Modified Kaolin

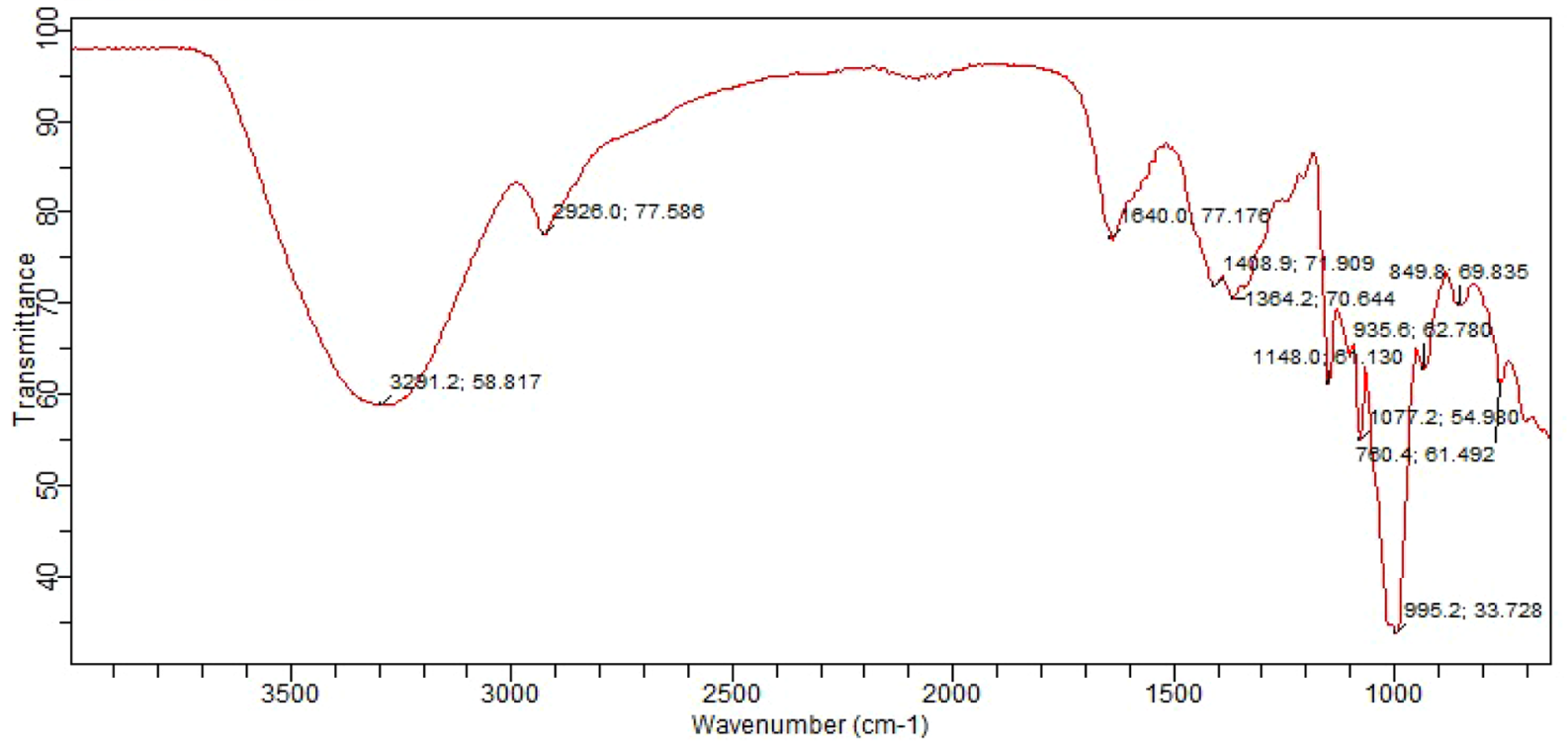

Fig. 3 FT-IR spectra of the raw and modified kaolin

that the adsorption capacities of both raw and modified kaolin increased with increase in contact time. Equilibrium adsorption of $\mathrm{Pb}$ (II) ions was reached in 20 min for the raw kaolin $(7.3 \mathrm{mg} / \mathrm{g})$ and $25 \mathrm{~min}$ for the modified kaolin $(20 \mathrm{mg} / \mathrm{g})$ after which the amount of metal ions adsorbed began to drop. There was a rapid uptake of $\mathrm{Pb}$ (II) metal ions by both adsorbents, which gradually slowed down until an equilibrium adsorption time was reached. The initial rapid adsorption rate can be attributed to surplus adsorption sites on the surface of the adsorbents which is constrained by dispersion from the mass to the surface of the adsorbent [19]. However, the active sites becomes saturated eventually, leading to subsequent slower adsorption rates as the equilibrium time is being approached which is most likely because of a connection controlled phenomenon [36].

\subsection{Effect of initial metal ion concentration}

The rate at which metal ions are adsorbed from their solution onto the surface of the adsorbents is a function of the initial metal ion concentration, thus, making it an important factor for an effective sorption [36]. Due to the fact that the raw and modified kaolin possesses a fixed number of active sites which became saturated at higher concentration, it was seen that the rate adsorption of $\mathrm{Pb}$ (II) 


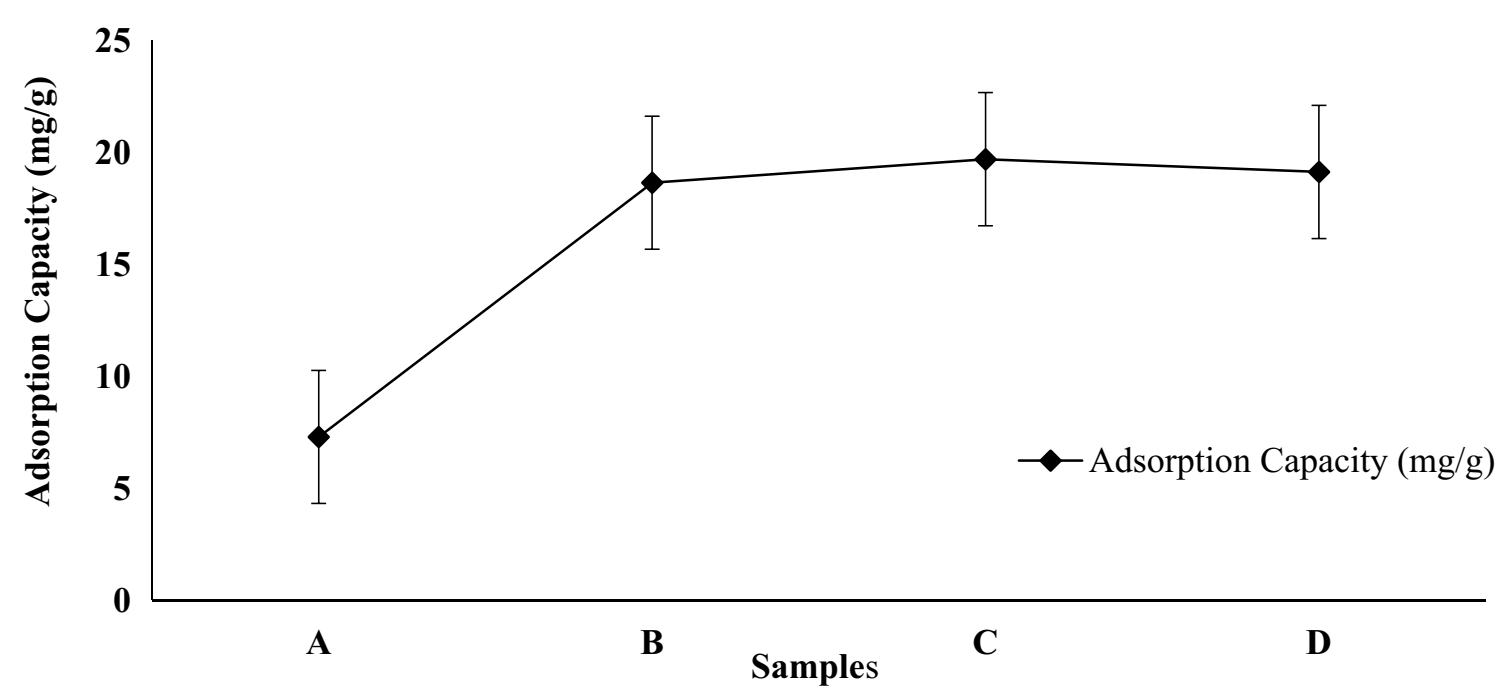

Fig. $4 \mathrm{~Pb}$ (II) adsorption performance assessment by the raw kaolin and all the modified samples

intensified with increment in the metal ion concentration [19] as shown in Fig. 6. Furthermore, the adsorption capacities of the adsorbents increased with increase in $\mathrm{Pb}(\mathrm{II})$ ions concentration due to the increasing concentration gradient as shown in Fig. 7, which counters the insulation to mass exchange of the metal ions between the metals and the kaolin species [36]. The linearity of the adsorption capacity of the modified kaolin shows that pore diffusion does not limit the adsorption process.

\subsection{Effect of adsorbent dosage}

As it can be observed from Fig. 8, the percentage of $\mathrm{Pb}$ (II) metal ions removed increased rapidly as the masses of the raw kaolin and modified kaolin was increased from 0.1 to $0.4 \mathrm{~g}$. this is because, as the masses of the adsorbent increases, the available binding sites on the surface of the adsorbent also increases [19]. However, an opposite pattern was observed as shown in Fig. 9 where

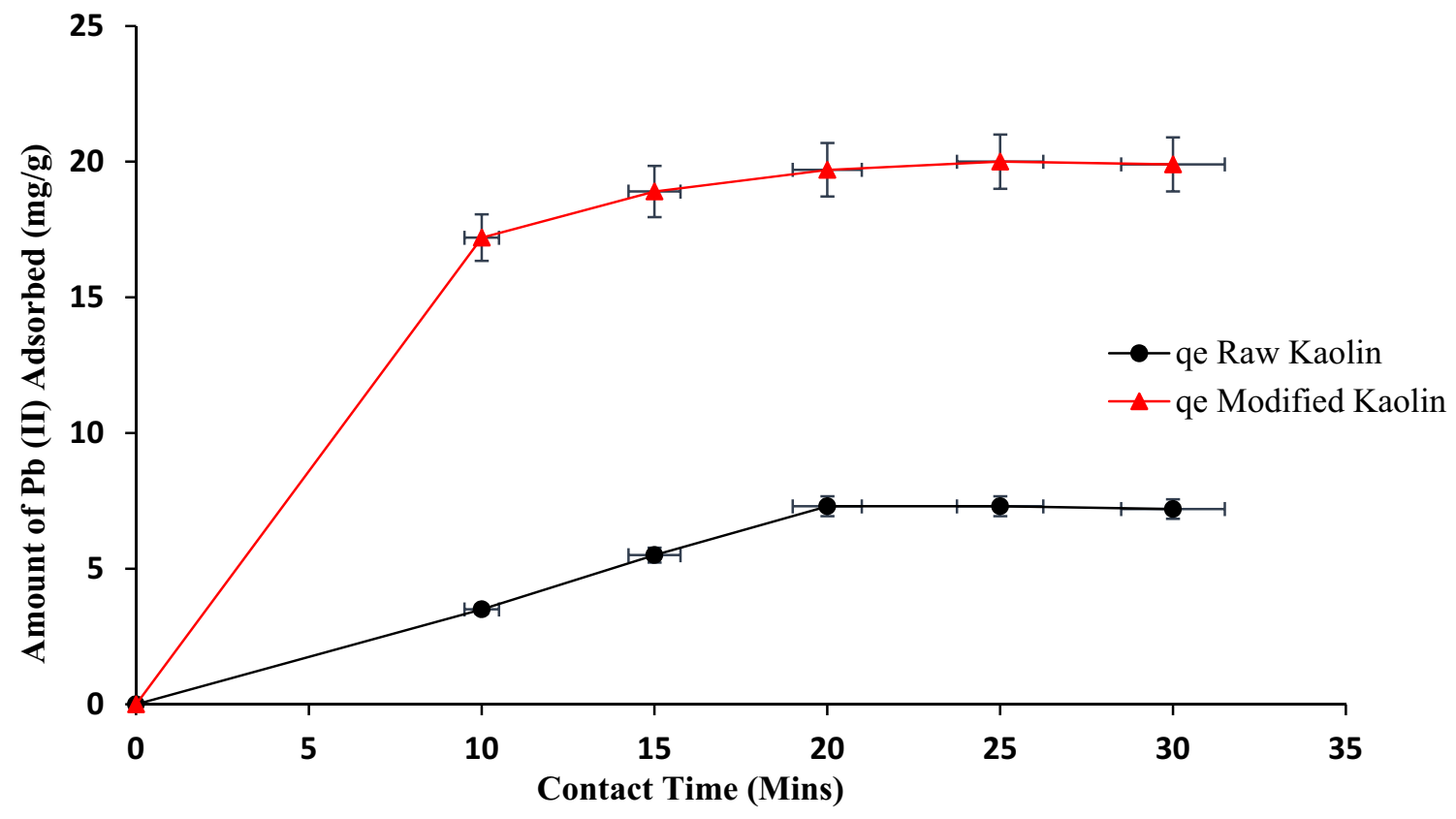

Fig. 5 Effect of contact time on the $\mathrm{Pb}(\mathrm{II})$ adsorption capacity of the raw and modified kaolin 


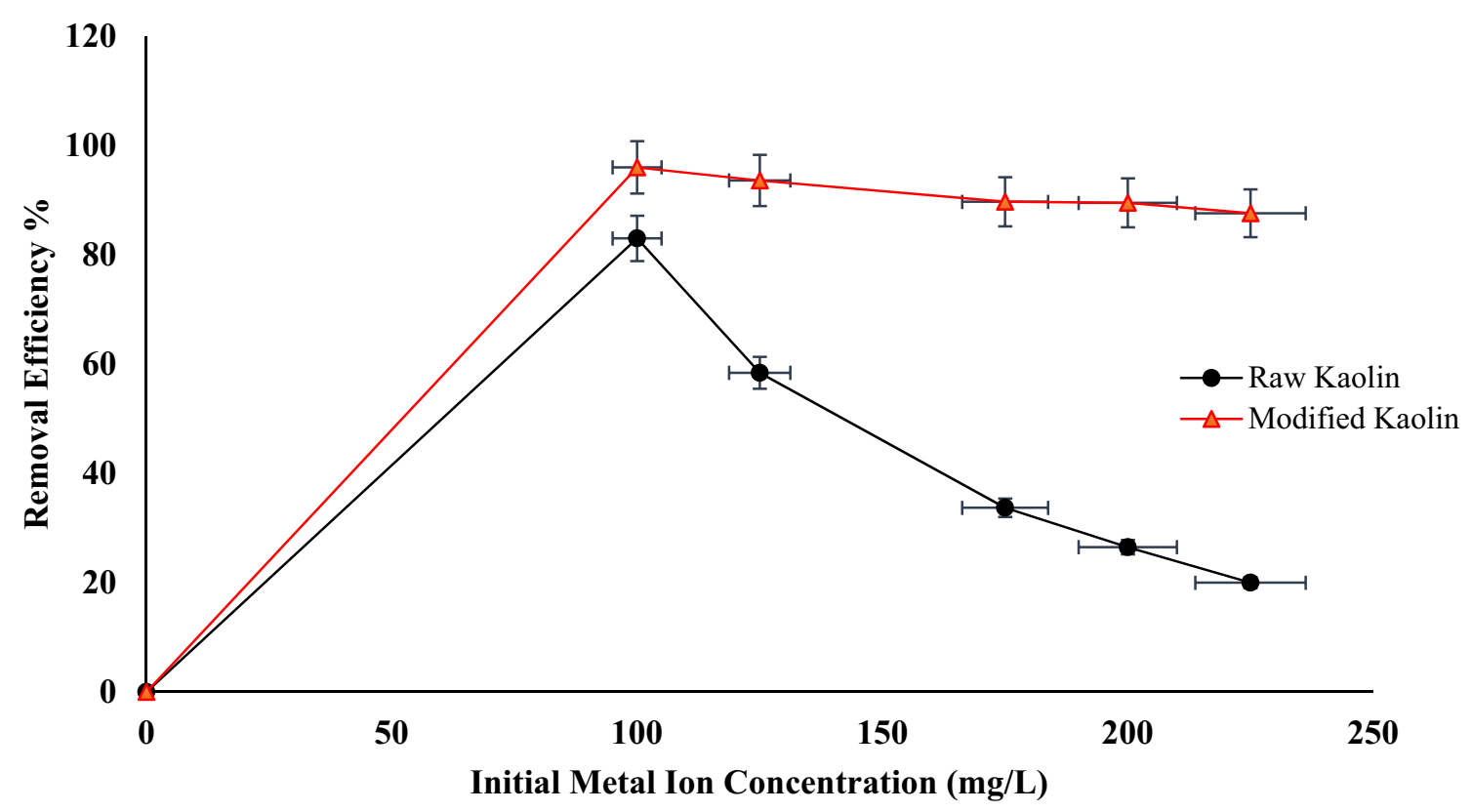

Fig. 6 Effect of initial concentration on the $\mathrm{Pb}$ (II) removal efficiency of the raw and modified kaolin

there was a decrease in adsorption capacity when the dosage of the modified kaolin was increased. Similar trend could also be observed with the raw kaolin. This phenomenon as reported by Dawodu and Akpomie [19] could be attributed to a decreasing adsorption surface area due to overlapping of adsorption sites.

\subsection{Adsorption isotherms}

The values of $\mathrm{q}_{\mathrm{L}}, \mathrm{K}_{\mathrm{L}}, \mathrm{K}_{\mathrm{F}}, \mathrm{n}, \mathrm{A}$ and $\mathrm{B}$ calculated from the Langmuir, Freundlich and Temkin models for the adsorption of $\mathrm{Pb}$ (II) onto the raw and modified kaolin are presented in Table 3. From the results, it was observed that the experimental data on the raw kaolin were well fitted

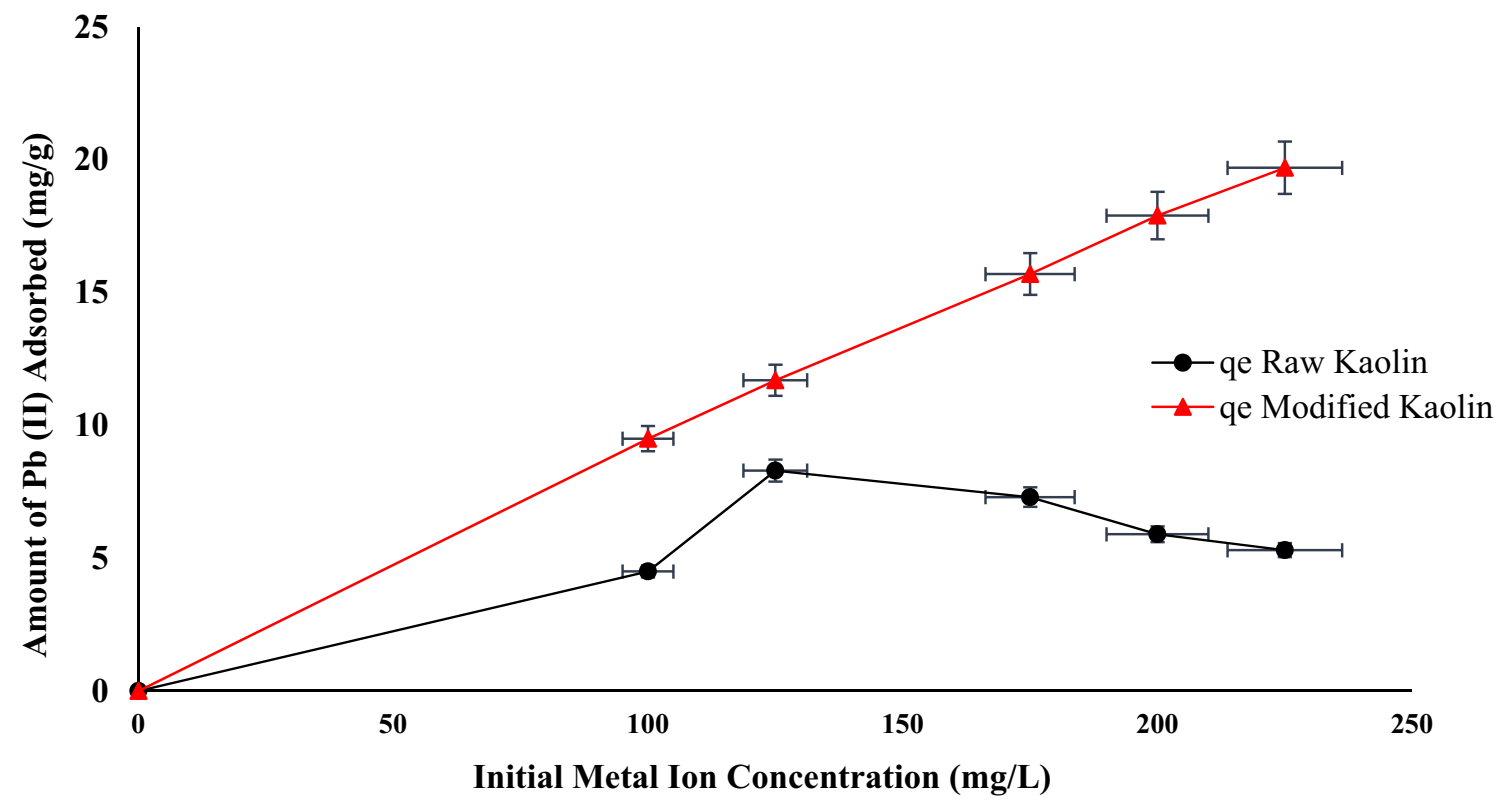

Fig. 7 Effect of initial concentration on the $\mathrm{Pb}(\mathrm{II})$ adsorption capacity of the raw and modified kaolin 


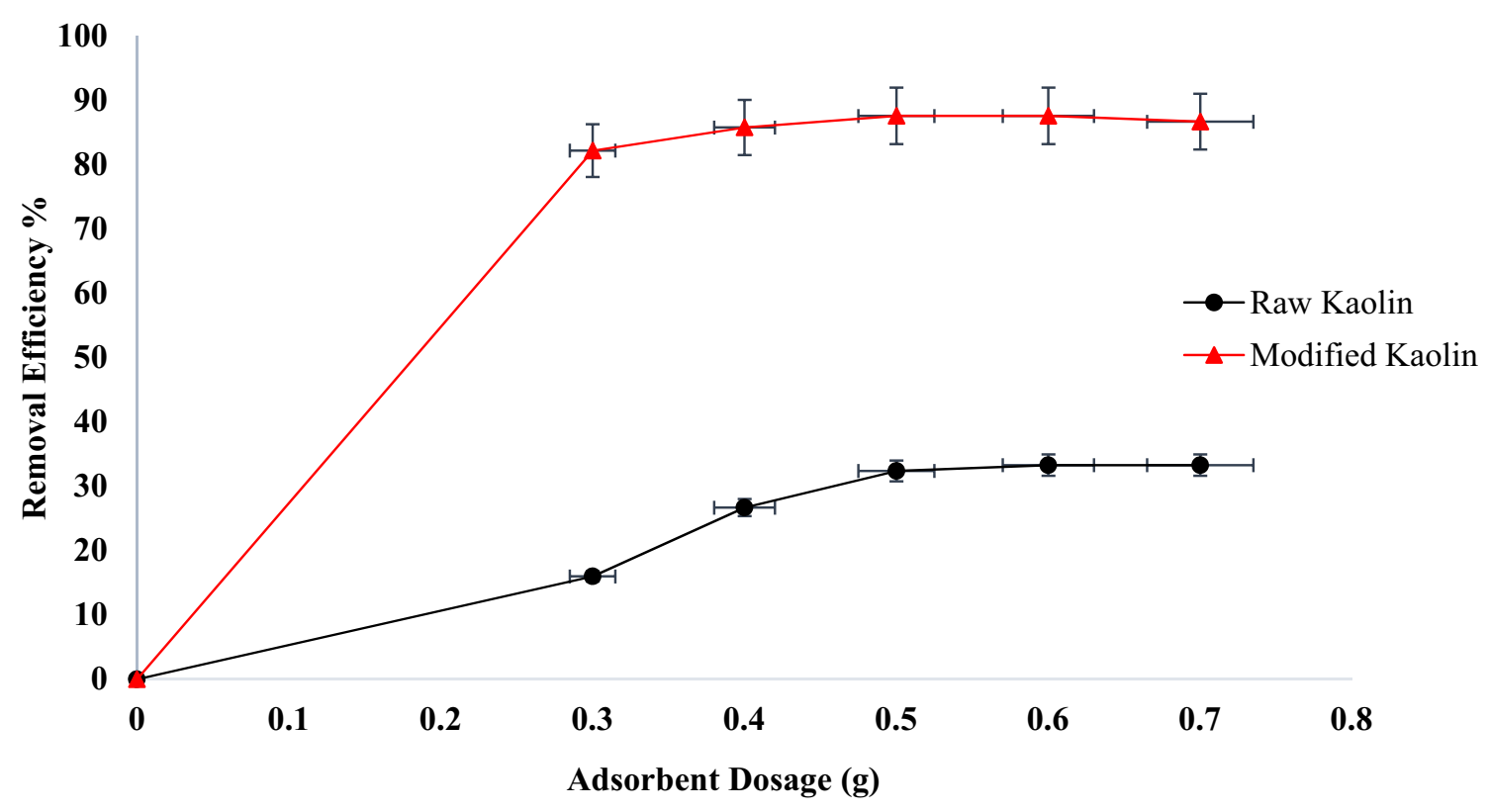

Fig. 8 Effect of adsorbent dosage on the $\mathrm{Pb}$ (II) removal efficiency of the raw and modified kaolin

to the Langmuir and Freundlich isotherm models with regression coefficients $\left(R^{2}\right) 0.9553$ and 0.9937 respectively, although, the later gave a better fit, describing a multilayer adsorption unto a heterogeneous surface of the raw kaolin [43]. The Freundlich constant $K_{F}$ calculated for the raw and modified kaolin were 4.8362 and 4.4576 respectively with the value of $\mathrm{n}$ greater than one in each case, indicating that the adsorptions were favourable and the process is physisorption [6]. The correlation coefficient $\left(R^{2}=0.9837\right)$ determined using the Langmuir isotherm model best describe the equilibrium properties of the modified kaolin in adsorbing $\mathrm{Pb}$ (II) ions. This relates to adsorption on a homogenous surface. From the Langmuir model, the calculated maximum adsorption capacity of the raw kaolin

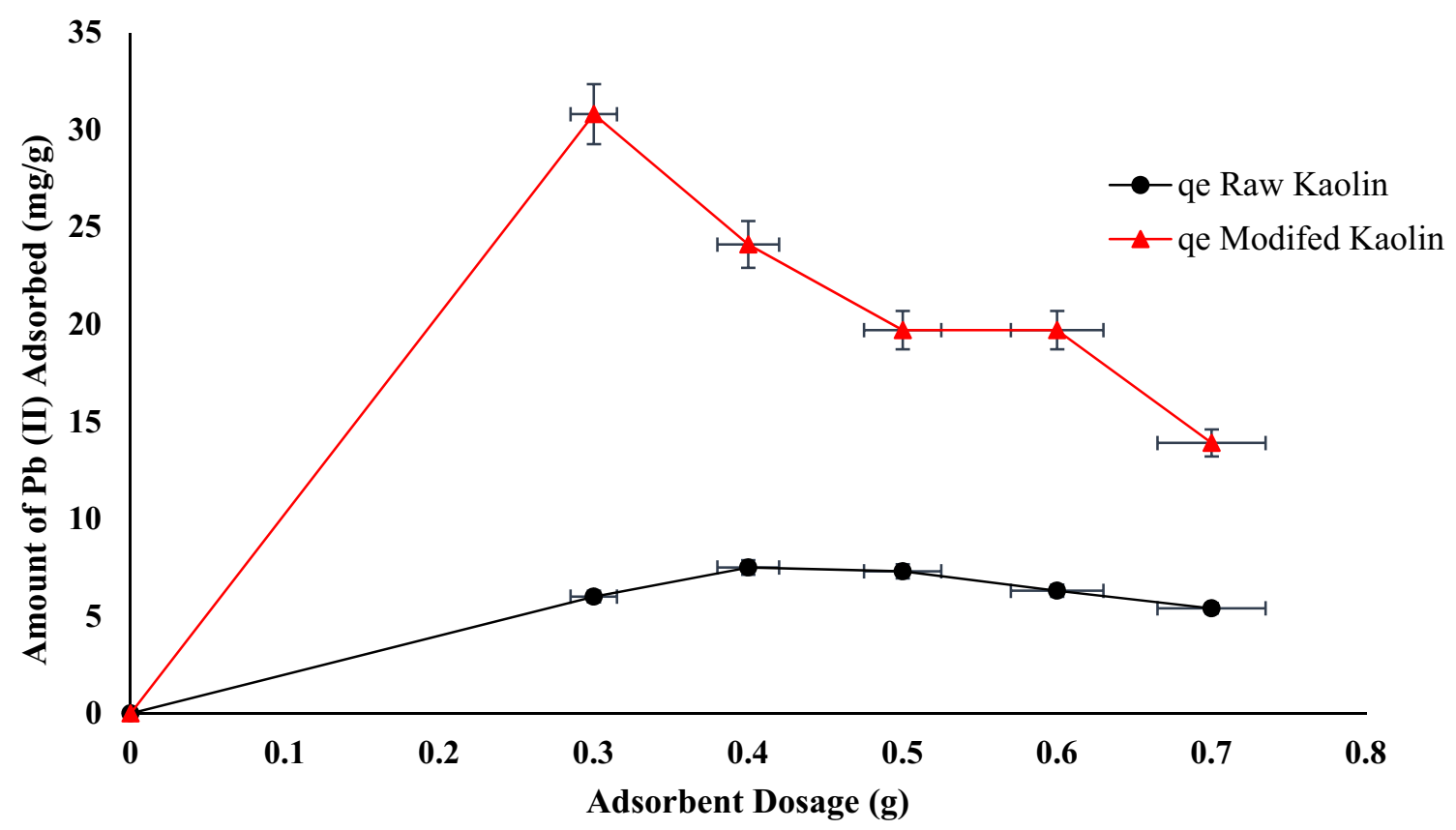

Fig. 9 Effect of adsorbent dosage on the $\mathrm{Pb}$ (II) adsorption capacity of the raw and modified kaolin 
Table 3 The parameters for Langmuir and Freundlich isotherms

\begin{tabular}{lcc}
\hline Isotherm models & Raw kaolin & Modified kaolin \\
\hline Langmuir model & & \\
$\mathrm{q}_{\mathrm{L}}(\mathrm{mg} / \mathrm{g})$ & 5.4230 & 25.6410 \\
$\mathrm{~K}_{\mathrm{L}}(\mathrm{L} / \mathrm{mg})$ & 0.2006 & 0.1064 \\
$\mathrm{R}^{2}$ & 0.9553 & 0.9837 \\
Freundlich model & & \\
$\mathrm{K}_{\mathrm{F}}(\mathrm{mg} / \mathrm{g})(\mathrm{L} / \mathrm{g})^{1 / \mathrm{n}}$ & 4.4576 & 4.8362 \\
$\mathrm{n}(\mathrm{g} / \mathrm{L})$ & 13.7741 & 2.3776 \\
$\mathrm{R}^{2}$ & 0.9937 & 0.0820 \\
Temkin model & & \\
$\mathrm{A}(\mathrm{L} / \mathrm{mg})$ & $4.1467 \times 10^{11}$ & $4.0450 \times 10^{-6}$ \\
$\mathrm{~B}(\mathrm{mg} / \mathrm{g})$ & 0.1316 & 0.2440 \\
$\mathrm{R}^{2}$ & 0.0435 & 0.5862 \\
\hline
\end{tabular}

Table 4 Comparison of the adsorption capacity of the modified kaolin with other adsorbents in $\mathrm{Pb}$ (II) removal

\begin{tabular}{lll}
\hline Adsorbent & $\mathrm{Q}_{\max }$ & Reference \\
\hline Modified rhizopus oryzae & 12.39 & {$[8]$} \\
Penaeuse semisulcatuse chitin & 13.14 & {$[44]$} \\
Modified kaolin & 32.20 & {$[32]$} \\
Modified montmorillonite & 1.62 & {$[31]$} \\
Oak powder/Fe $\mathrm{O}_{4}$ & 54.95 & {$[45]$} \\
This work & 25.64 &
\end{tabular}

was $5.4230 \mathrm{mg} / \mathrm{g}$ while that of modified kaolin was calculated to be $25.6410 \mathrm{mg} / \mathrm{g}$. This is to say that the hydrothermal treatment increased the pore and active surface of the kaolin, which corroborates the BET results [43], hence, largely enhancing its adsorption capacity as reported by Jiang et al. [32]. The modified kaolin performed well in comparison with other adsorbents $[8,31,32,44,45]$ that have been used to remove $\mathrm{Pb}(\mathrm{II})$ ions as shown in Table 4 . The separation factor $R_{L}$, calculated from the Langmuir plot fell between the ranges of 0.0004 to 0.0008 for the raw kaolin and 0.0004 to 0.0009 for the modified kaolin showing that the adsorptions are favorable. Both raw and modified kaolin samples fitted poorly into the Temkin model with a very low regression coefficient $(0.0435$ and 0.5862 respectively).

\section{Conclusion}

The effects of thermal activation and alkaline hydrothermal treatment on the structural and chemical properties of Enugu kaolin using different concentrations of $\mathrm{NaOH}$ and reaction time were studied. XRF analysis suggested that the hydrothermal treatments made weak alterations to the chemical composition of the parent kaolin clay. However, results from XRF analysis also showed that the dissolution of Si prevailed over $\mathrm{Al}$, furthermore, the insertion of $\mathrm{Na}^{+}$ into the kaolin structure was confirmed. XRD and FTIR spectra of the raw and modified kaolin shows similar peaks suggesting that the modification process had no significant alterations to the internal structure of the kaolin. SEM micrographs displayed spherical morphology in the modified kaolin compared to the complete amorphous form of the raw kaolin. BET surface area and pore volumes of all the treated samples were found to have increased significantly when compared to the parent kaolin, there was a decrease in pore diameter of the treated samples relative to the starting raw kaolin. Results obtained from the adsorption of $\mathrm{Pb}$ (II) from aqueous solution suggested that the modification of the kaolin enhances $\mathrm{Pb}$ (II) removal significantly, and the process could be replicated on a pilot scale with real waste water. Furthermore, the adsorption of $\mathrm{Pb}$ (II) by the raw kaolin followed the Freundlich model while that of the modified kaolin fitted better to the Langmuir model. Therefore, based on the surface analysis and adsorption experiments, Enugu kaolin has a potential to be a catalyst-type material and the modification method employed can be useful in affording materials that could be applied in various related industries which requires a porous and high surface area of the clay material.

Authors contributions UC was the lead supervisor of this project. KG provided plagiarism reports. OC proofread and edited the manuscript. $\mathrm{HO}$ analyzed and interpreted isotherm models for the study. All authors have read and approved the manuscript

\section{Compliance with ethical standards}

Conflict of interest The authors declare that they have no conflict of interests.

Availability of data and materials The data generated and/or analyzed during this study are available from the corresponding author on reasonable request.

\section{References}

1. Orjoke NM, Okoro UC, Igwe CN, Ajah UN (2015) Synthesis and characterization of zeolite and its application in adsorption of nickel from aqueous solution. J Pharm Chem Biol Sci 3(4):592-600

2. Ahmadi SJ, Sadjadi S, Hosseinpour M (2012) Adsorption behavior of toxic metal ions on nano-structured $\mathrm{CuO}$ granules. Sep Sci Technol 47(7):1063-1069. https://doi.org/10.1080/01496 395.2011.631675

3. Foroutan R, Mohammadi R, Farjadfard S, Esmaeili $\mathrm{H}$, Ramavandi B, Sorial GA (2019) Eggshell nano-particle potential for methyl 
violet and mercury ion removal: surface study and field application. Adv Powder Technol 30(10):2188-2199. https://doi. org/10.1016/j.apt.2019.06.034

4. Arim AL, Guzzo G, Quina MJ, Gando-Ferreira LM (2018) Single and binary sorption of $\mathrm{Cr}$ (III) and $\mathrm{Ni}$ (II) onto modified pine bark. Environ Sci Pollut Res 25(28):28039-28049. https://doi. org/10.1007/s11356-018-2843-z

5. Foroutan $\mathrm{R}$ et al (2019) Characteristics and performance of $\mathrm{Cd}$, $\mathrm{Ni}$, and $\mathrm{Pb}$ bio-adsorption using Callinectes sapidus biomass: real wastewater treatment. Environ Sci Pollut Res 26(7):6336-6347. https://doi.org/10.1007/s11356-018-04108-8

6. Abshirini Y, Foroutan R, Esmaeili $\mathrm{H}$ (2019) $\mathrm{Cr}(\mathrm{VI})$ removal from aqueous solution using activated carbon prepared from Ziziphus spina-christi leaf. Mater Res Express 6(4):045607. https ://doi.org/10.1088/2053-1591/aafb45

7. Ahmadi A, Foroutan R, Esmaeili $\mathrm{H}$, Tamjidi S (2020) The role of bentonite clay and bentonite clay@ $\mathrm{MnFe}_{2} \mathrm{O}_{4}$ composite and their physico-chemical properties on the removal of $\mathrm{Cr}(\mathrm{III})$ and $\mathrm{Cr}(\mathrm{VI})$ from aqueous media. Environ Sci Pollut Res. https://doi. org/10.1007/s11356-020-07756-x

8. Naeimi B, Foroutan R, Ahmadi B, Sadeghzadeh F, Ramavandi B (2018) $\mathrm{Pb}$ (II) and $\mathrm{Cd}$ (II) removal from aqueous solution, shipyard wastewater, and landfill leachate by modified Rhizopus oryzae biomass. Mater Res Express 5(4):045501. https://doi. org/10.1088/2053-1591/aab81b

9. Foroutan R, Mohammadi R, Ramavandi B, Bastanian M (2018) Removal characteristics of chromium by activated carbon/ $\mathrm{CoFe}_{2} \mathrm{O}_{4}$ magnetic composite and Phoenix dactylifera stone carbon. Korean J Chem Eng 35(11):2207-2219. https://doi. org/10.1007/s11814-018-0145-2

10. Barczak M, Michalak-Zwierz K, Gdula K, Tyszczuk-Rotko K, Dobrowolski R, Dąbrowski A (2015) Ordered mesoporous carbons as effective sorbents for removal of heavy metal ions. Microporous Mesoporous Mater 211:162-173. https://doi. org/10.1016/j.micromeso.2015.03.010

11. Karnib M, Kabbani A, Holail H, Olama Z (2014) Heavy metals removal using activated carbon, silica and silica activated carbon composite. Energy Procedia 50:113-120. https://doi. org/10.1016/j.egypro.2014.06.014

12. Meroufel B, Zenasni MA (2019) Preparation, characterization, and heavy metal ion adsorption property of APTES-modified kaolin: comparative study with original clay. In: Hussain CM (ed) Handbook of environmental materials management. Springer, Cham, pp 1167-1190

13. Edama NA, Sulaiman A, Ku Hamid KH, Rodhi MNM, Musa M, Rahim SNA (2014) The effect of hydrochloric acid on the surface area, morphology and physico-chemical properties of sayong kaolinite clay. Key Eng Mater 594-595:49-56. https:// doi.org/10.4028/www.scientific.net/KEM.594-595.49

14. Kumar S, Panda AK, Singh RK (2013) Preparation and characterization of acids and alkali treated kaolin clay. Bull Chem React Eng Catal 8(1):61-69. https://doi.org/10.9767/bcrec 8.1.4530.61-69

15. Hussin F, Aroua MK, Daud WMAW (2011) Textural characteristics, surface chemistry and activation of bleaching earth: a review. Chem Eng J 170(1):90-106. https://doi.org/10.1016/j. cej.2011.03.065

16. Al-Essa K (2018) Heavy metals adsorption from aqueous solutions onto unmodified and modified jordanian kaolinite clay: batch and column techniques. Am J Appl Chem 6(1):25. https ://doi.org/10.11648/j.ajac.20180601.14

17. Struijk M, Rocha F, Detellier C (2017) Novel thio-kaolinite nanohybrid materials and their application as heavy metal adsorbents in wastewater. Appl Clay Sci 150:192-201. https://doi. org/10.1016/j.clay.2017.09.024
18. Fida H, Guo S, Zhang G (2015) Preparation and characterization of bifunctional Ti-Fe kaolinite composite for $\mathrm{Cr}(\mathrm{VI})$ removal. J Colloid Interface Sci 442:30-38. https://doi.org/10.1016/j. jcis.2014.11.023

19. Dawodu FA, Akpomie KG (2014) Simultaneous adsorption of $\mathrm{Ni}(\mathrm{II})$ and $\mathrm{Mn}$ (II) ions from aqueous solution unto a Nigerian kaolinite clay. J Mater Res Technol 3(2):129-141. https://doi. org/10.1016/j.jmrt.2014.03.002

20. Amer MW, Khalili Fl, Awwad AM (2010) Adsorption of lead, zinc and cadmium ions on polyphosphate-modified kaolinite clay. Environ Chem 2(1):001-008

21. Belver C, Bañares Muñoz MAB, Vicente MA (2002) "Chemical activation of a kaolinite under acid and alkaline conditions. Chem Mater 14(5):2033-2043. https://doi.org/10.1021/cm0111736

22. Ismail MA, Eltayeb MAZ, Maged SAA (2013) Synthesis of zeolite A from sudanese montmorillonite clay to remove nickel and copper ions from aqueous solutions. Int J Chem Biochem Sci 4:46-56

23. Mostafa AA, Youssef HF, Materials A (2011) Utilization of Egyptian kaolin for Zeolite-A preparation and performance evaluation. Int Conf Environ Sci Technol 6:43-48

24. Johnson EBG, Arshad SE, Asik J (2014) Hydrothermal synthesis of zeolite A using natural kaolin from KG. Gading bongawan sabah. J Appl Sci 14(23):3282-3287. https://doi.org/10.3923/ jas.2014.3282.3287

25. Dudkin B, Loukhina I, Avvakumov E, Isupov V (2004) Application of mechanochemical treatment of disintegration of kaolinite with sulphuric acid. J Sustain Dev 12:327-330

26. Panda AK, Mishra BG, Mishra DK, Singh RK (2010) Effect of sulphuric acid treatment on the physico-chemical characteristics of kaolin clay. Colloids Surf A Physicochem Eng Asp 363(1-3):98104. https://doi.org/10.1016/j.colsurfa.2010.04.022

27. Jozefaciuk G, Bowanko G (2002) Effect of acid and alkali treatments on surface areas and adsorption energies of some selected minerals. Clays Clay Miner 50(6):771-783. https://doi. org/10.1346/000986002762090308

28. Lenarda M, Storaro L, Talon A, Moretti E, Riello P (2007) Solid acid catalysts from clays: preparation of mesoporous catalysts by chemical activation of metakaolin under acid conditions. J Colloid Interface Sci 311(2):537-543. https://doi.org/10.1016/j. jcis.2007.03.015

29. Srasra E, Trabelsi-Ayedi M (2000) Textural properties of acid activated glauconite. Appl Clay Sci 17(1-2):71-84. https://doi. org/10.1016/S0169-1317(00)00008-9

30. Taubald H, Bauer A, Scha T, Geckeis H, Satir M (2000) Experimental investigation of the effect of high-pH solutions on the Opalinus Shale and the Hammerschmiede Smectite. Clay Miner 35(3):515-524. https://doi.org/10.1180/000985500546981

31. Akpomie KG, Dawodu FA (2016) Acid-modified montmorillonite for sorption of heavy metals from automobile effluent. BeniSuef Univ J Basic Appl Sci 5(1):1-12. https://doi.org/10.1016/j. bjbas.2016.01.003

32. Jiang $M$, Wang $Q$, Jin $X$, Chen $Z$ (2009) Removal of $P b$ (II) from aqueous solution using modified and unmodified kaolinite clay. J Hazard Mater 170(1):332-339. https://doi.org/10.1016/j.jhazm at.2009.04.092

33. Langmuir I (1918) The adsorption of gases on plane surfaces of glass, mica and platinum. J Am Chem Soc 40(9):1361-1403. https://doi.org/10.1021/ja02242a004

34. Fruendlich HMF (1906) Over the adsorption in solution. J Phys Chem 57:385-471

35. Nematollahzadeh A, Abdekhodaie MJ, Shojaei A (2012) Submicron nanoporous polyacrylamide beads with tunable size for verapamil imprinting. J Appl Polym Sci 125(1):189-199. https ://doi.org/10.1002/app.35426 
36. Emam AA, Ismail L, AbdelKhalek M (2016) Adsorption study of some heavy metal ions on modified kaolinite clay. Int J Adv Eng Technol 03(07):152-163

37. Akpomie KG, Dawodu FA (2014) Efficient abstraction of nickel(II) and manganese(II) ions from solution onto an alkaline-modified montmorillonite. J Taibah Univ Sci 8(4):343-356

38. José V, Gláucia M, Rodrigues F (2015) Synthesis and characterization of ZSM-5 zeolite using kaolin as Si and Al source. Mater Sci Forum 805:651-656. https://doi.org/10.4028/www.scientific .net/MSF.805.651

39. Khatamian M, Irani M (2009) Preparation and characterization of nanosized ZSM-5 zeolite using kaolin and investigation of kaolin content, crystallization time and temperature changes on the size and crystallinity of products. J Iran Chem Soc 6(1):187-194. https://doi.org/10.1007/BF03246519

40. Shaikh IR et al (2015) H-ZSM-5 zeolite synthesis by sourcing silica from the wheat husk ash: characterization and application as a versatile heterogeneous catalyst in organic transformations including some multicomponent reactions. J Catal 2015:1-14. https://doi.org/10.1155/2015/805714

41. Foroutan $\mathrm{R}$ et al (2019) Efficient arsenic(V) removal from contaminated water using natural clay and clay composite adsorbents. Environ Sci Pollut Res 26(29):29748-29762. https://doi. org/10.1007/s11356-019-06070-5
42. Foroutan R, Zareipour R, Mohammadi R (2018) Fast adsorption of chromium $(\mathrm{VI})$ ions from synthetic sewage using bentonite and bentonite/bio-coal composite: a comparative study. Mater Res Express 6(2):025508. https://doi.org/10.1088/2053-1591/ aaebb9

43. Foroutan $\mathrm{R}$ et al (2020) Calcined alluvium of agricultural streams as a recyclable and cleaning tool for cationic dye removal from aqueous media. Environ Technol Innov 17:100530. https://doi. org/10.1016/j.eti.2019.100530

44. Esvandi Z, Foroutan R, Mirjalili M, Sorial GA, Ramavandi B (2019) Physicochemical behavior of Penaeuse semisulcatuse chitin for $\mathrm{Pb}$ and $\mathrm{Cd}$ removal from aqueous environment. J Polym Environ 27(2):263-274. https://doi.org/10.1007/s10924-018-1345-x

45. Shafiee $M$, Foroutan $R$, Fouladi $K$, Ahmadlouydarab $M$, Ramavandi B, Sahebi S (2019) Application of oak powder $/ \mathrm{Fe}_{3} \mathrm{O}_{4}$ magnetic composite in toxic metals removal from aqueous solutions. Adv Powder Technol 30(3):544-554. https://doi.org/10.1016/j. apt.2018.12.006

Publisher's Note Springer Nature remains neutral with regard to jurisdictional claims in published maps and institutional affiliations. 